This item was submitted to Loughborough's Research Repository by the author.

Items in Figshare are protected by copyright, with all rights reserved, unless otherwise indicated.

\title{
The role of companions in outpatient seizure clinic interactions: a pilot study
}

PLEASE CITE THE PUBLISHED VERSION

http://dx.doi.org/10.1016/j.yebeh.2016.04.010

\section{PUBLISHER}

(c) Elsevier

VERSION

AM (Accepted Manuscript)

\section{PUBLISHER STATEMENT}

This work is made available according to the conditions of the Creative Commons Attribution-NonCommercialNoDerivatives 4.0 International (CC BY-NC-ND 4.0) licence. Full details of this licence are available at: https://creativecommons.org/licenses/by-nc-nd/4.0/

\section{LICENCE}

CC BY-NC-ND 4.0

\section{REPOSITORY RECORD}

Robson, Catherine, Paul Drew, and Markus Reuber. 2019. "The Role of Companions in Outpatient Seizure Clinic Interactions: A Pilot Study". figshare. https://hdl.handle.net/2134/23053. 
Published in Epilepsy \& Behaviour 60 (2016) 86-93

\section{Article title}

The role of companions in outpatient seizure clinic interactions: a pilot study.

\section{Authors}

Catherine Robson*, Paul Drew \& Markus Reuber

\section{Affiliations}

${ }^{*}$ Corresponding author: Catherine Robson

Affiliation address: Centre for Advanced Study in Language and Communication, University of York, Heslington, York, YO10 5DD.

Telephone: $+27(0) 613607841$

Email: catherinemaryrobson@gmail.com

Paul Drew, School of Social Sciences, Loughborough University, Loughborough, UK.

Email: p.drew@lboro.ac.uk

Markus Reuber, Academic Neurology Unit, University of Sheffield, Royal Hallamshire Hospital, Sheffield, UK.

Email: markus.reuber@sth.nhs.uk 


\section{Article title}

The role of companions in outpatient seizure clinic encounters: a pilot study.

\section{Keywords}

Epilepsy; PNES; differential diagnosis; provider-patient communication; third parties; Discourse Analysis; Conversation Analysis

\section{Structured Abstract}

\section{Objective}

This study explores contributions patients' companions (seizure-witnesses) make to interactions in the seizure clinic and whether the nature of the companions' interactional contributions can help with the differentiation of epilepsy and psychogenic nonepileptic seizures (PNES).

\section{Methods}

Microanalytic methods inspired by Conversation Analysis were used to examine video recordings and transcripts of neurologists' interactions with patients referred to a specialist seizure clinic and their companions.

\section{Results}

Patients with PNES but not those with epilepsy tended to exhibit interactional resistance to the doctor's efforts to find out more about their seizure experiences, and thereby encouraged greater interactional contribution from companions.

\section{Conclusion}

The contributions that companions make (in part prompted by patient's interactional behaviour) may provide additional diagnostic pointers in this clinical setting. However, companion contributions may limit the doctor's ability to identify linguistic and interactional features with previously demonstrated diagnostic potential in the conversational contributions made by patients themselves. 


\section{Practical implications}

A number of candidate features that may help clinicians distinguish between epilepsy and PNES when the patient is accompanied by a seizure-witness are described. To help offset potential diagnostic losses, doctors may need explicitly to discuss the role of the companion in the consultation when a seizure witness (or other companion) accompanies the patient.

\section{Highlights}

- Patients with PNES, but not epilepsy, tended to exhibit interactional resistance.

- Patient resistance encouraged greater interactional contribution from companions.

- The contributions of companions may provide additional diagnostic pointers.

- Doctors may need explicitly to discuss the roles of companions in this setting. 


\section{Introduction}

Qualitative researchers have studied doctor-patient interactions since at least the 1960s. More recently, qualitative (microanalytic) methods of studying interaction have been used diagnostically - assessing patients interactional behaviour to help identify and distinguish between medical conditions [1-4].

Predominantly applied in neurological settings, this use of qualitative methods marks a new and important field of enquiry for researchers exploring doctor-patient interactions, and for clinicians in these diagnostic fields. There is now a substantial body of work that demonstrates the diagnostic potential of microanalytic, sociolinguistic and Conversation Analysis (CA) inspired observations that can be made in the talk of PNES and epileptic seizure patients and in patients with functional and neurodegenerative memory complaints, when they speak to a neurologist. To date these studies have been carried out with German, English and Italian speakers [5].

Most of these studies have focused on patients seeking advice about seizures. Unlike epileptic seizures, PNES are not the result of abnormal electrical discharges in the brain, but are generally interpreted as physical manifestations of psychological distress [6-7]. PNES and epileptic seizures have superficially similar visible manifestations and differentiating between the two can be difficult. Yet it is crucial to get the diagnosis right because the choice of treatment critically depends on the cause and nature of the seizures. People with epilepsy are treated with anti-epileptic drugs, and people with PNES may benefit from psychotherapy. Despite advances in biomedical technologies, interictal tests such as brain magnetic resonance imaging (MRI) and electroencephalogram (EEG) have inadequate specificity and sensitivity in this setting [8-9]. The diagnostic "gold standard", the video-electroencephalographic recording (video-EEG) of a typical seizure can be difficult to access, or its use may not be feasible because of the low frequency of attacks [10]. Consequently, the act of taking and interpreting the history remains the most crucial part of the diagnostic process for seizure disorders. 
So far, most studies aiming to help with the differential diagnosis of patients with seizures have focussed on encounters in which patients talked to doctors on their own. However, patients with seizures are routinely invited to bring along a companion when they attend outpatient appointments. National guidelines and studies focusing on the risk of misdiagnosis underline the importance of obtaining descriptions not only from patients but also from witnesses of attacks [1114].

In this pilot study we examine the contributions patients' companions make to interactions in the seizure clinic and explore whether the companions' contributions yield additional diagnostic pointers to the diagnoses of epilepsy or PNES.

\section{Methods}

\subsection{Participants}

To explore the contribution of companions to seizure clinic encounters we recruited 50 patients (aged over 18 years) attending the specialist clinics of one of two participating fully trained specialists in the assessment of seizure disorders at the Royal Hallamshire Hospital (Sheffield, UK) between January 2010 and March 2012. Patients were eligible for inclusion if they had been referred to the clinic for a first initial (diagnostic) consultation. Inclusion and exclusion criteria are detailed in table 1. Consecutive eligible patients (and where applicable their companions) were invited to take part, and if they agreed provided written informed consent to participate. The consultant neurologists participating in the interactions were encouraged to conduct consultations in their usual manner, and not to modify their routine history-taking method for this study. Researchers were not present during the consultations, which were filmed using a stand-alone device. Detailed verbatim transcripts of all recordings were produced.

Consultations were selected for inclusion in this study according to systematic criteria designed to create a homogenous sample of PNES and epilepsy patients (see table 1). All consultations 
involving patients diagnosed with PNES or epilepsy who were accompanied to their appointment by a spouse or partner who had witnessed at least one of their seizure episodes were identified.

The diagnoses of PNES or epilepsy were confirmed by the patient's Consultant Neurologist six months after the original assessment when test results were available and initial treatment outcomes were known. All patients were investigated with MRI, interictal EEG and ECG. Some diagnoses had been confirmed by video-EEG by the end of this study.

\section{Table 1. Inclusion and Exclusion Criteria}

\begin{tabular}{|c|c|}
\hline $\begin{array}{l}\text { Study } \\
\text { exclusion } \\
\text { criteria }^{1}\end{array}$ & $\begin{array}{l}\text { - not fluent in English; or } \\
\text { - has learning disabilities; or } \\
\text { - has previously assessed for major neurological surgical intervention. }\end{array}$ \\
\hline $\begin{array}{l}\text { Sample } \\
\text { inclusion } \\
\text { criteria }\end{array}$ & $\begin{array}{l}\text { - the patient was accompanied to their appointment by a companion }(31 / 49 \text { patients })^{2} \text {; and } \\
\text { - a diagnosis of PNES or epilepsy was confirmed by the consultant neurologist at six-month } \\
\text { follow-up (23/31); and } \\
\text { - the patient was accompanied by a companion that had witnessed a seizure event }(16 / 23) \text {; and } \\
\text { - the companion was the patients' spouse or partner }{ }^{3}(13 / 16) \text {. }\end{array}$ \\
\hline
\end{tabular}

'This information was gathered from the patients' medical records prior to their attendance at the clinic. If uncertainty remained, patients (and where applicable, their companions) were approached while they waited to be seen, informed about the study, and inclusion/exclusion criteria were discussed and checked.

${ }^{2}$ To ensure comparability, one interaction, concerning an accompanied patient with (expressive) aphasia (attending with their spouse) was removed at this stage.

${ }^{3}$ We considered that accompanying persons who were the parents or friends of patients might interact differently to their spouses or partners.

\subsection{Data analysis}

Clinical and demographic differences between PNES and epilepsy patient groups, and differences between participant discourse spaces and the lengths (minutes) of PNES and epilepsy patient consultations were analysed using non-parametric statistical methods. Two-sided p-values of $<0.05$ were considered statistically significant throughout.

To help ensure comparability between the PNES and epilepsy patient groups, the discourse spaces of participants (the number of words spoken by a particular participant as a proportion of the total number of words spoken by all participants in the interaction) were calculated, and the discourse space 'structures' of consultations assessed (for an overview of methods, see Robson, Drew and Reuber [15]). The topical content of consultation history-taking phases was thematically analysed using Discourse Analysis methods according to "what gets talked about" [16]. 
History-taking phases containing patient and companion descriptions of attacks and discussions of periods of reduced patient consciousness and unconsciousness became the focus of Conversation Analysis (CA) inspired analysis. As described by Drew and Heritage [17], CA is the systematic analysis of the sequence and organisation (verbal and non-verbal) of 'naturally occurring' interactions; "the goal is to identify the patterns, practices or devices which underlie meaning and action" (p.9). The method has been widely applied in the study of doctor-patient interactions [18].

The methods used in this study utilised CA's microanalytic focus on the close sequential analysis of turns-at-talk. However, analyses included targets of inference beyond (larger than) those traditionally examined by conversation analysts, and findings were open to greater subjective interpretation. In this sense, our approach is in line with the interdisciplinary application of discourse analytical methodology, and comparable to the discourse work of Sarangi and Roberts [16].

The turns-at-talk and the conversational activities of participants leading up to the point at which companions 'gained the floor' [19-20] to describe what they had witnessed and to 'tell their story' were the particular focus of analysis.

\section{Results}

Of the 50 consultations recorded, 13 were identified in which patients with epilepsy or PNES were accompanied by a spouse who had witnessed at least one seizure (six of these patients had epilepsy, seven PNES).

\subsection{Clinical and demographic features}

There were no significant differences between the epilepsy and the PNES patient samples in terms of age or gender ratio. There was a significant difference in the lengths of the PNES and epilepsy patient consultations, as measured in their entirety. However, there was no significant difference in 
the lengths of history-taking phases of PNES and epilepsy consultations (see table 2). Typically, proportionally lengthier exchanges about the explanation of the condition, its aetiology and best treatment were found in PNES consultations compared to epilepsy consultations.

Table 2: Clinical and demographic features of PNES and epilepsy patient groups

\begin{tabular}{|c|c|c|c|c|}
\hline & & $\begin{array}{r}\text { PNES cases } \\
(n=7)\end{array}$ & $\begin{array}{r}\text { Epilepsy cases } \\
(n=6)\end{array}$ & $\begin{array}{r}\text { PNES vs. } \\
\text { Epilepsy } \\
\text { Significance of } \\
\text { difference }\end{array}$ \\
\hline & $\begin{array}{l}\text { Median length (and range) of } \\
\text { entire consultations (minutes) }\end{array}$ & $\begin{array}{r}34.2 \\
(11.4 \text { to } 58.1) \\
\end{array}$ & $\begin{array}{r}18.8 \\
(10.2 \text { to } 24.2) \\
\end{array}$ & $p=0.027^{*}$ \\
\hline & $\begin{array}{l}\text { Median length (and range) of } \\
\text { history taking phases } \\
\text { (minutes) }\end{array}$ & $\begin{array}{r}20.4 \\
(6.2 \text { to } 37.2)\end{array}$ & (8.1 to 19.2$)$ & n.s* \\
\hline \multirow{2}{*}{$\begin{array}{l}\text { Consultation } \\
\text { undertaken by: }\end{array}$} & Doctor A & 1 & 6 & \multirow[t]{2}{*}{$p=0.005^{V}$} \\
\hline & Doctor B & 6 & 0 & \\
\hline \multirow[t]{4}{*}{ Age (rage) } & 20 to 35 years & 1 & 2 & \multirow[t]{4}{*}{ n.s s $^{\wedge}$} \\
\hline & 36 to 50 years & 4 & 1 & \\
\hline & 51 to 64 years & 2 & 2 & \\
\hline & $65+$ years & 0 & 1 & \\
\hline \multirow[t]{2}{*}{ Patient gender } & Male & 3 & 5 & \multirow[t]{2}{*}{ n.s ${ }^{V}$} \\
\hline & Female & 4 & 1 & \\
\hline \multirow{2}{*}{$\begin{array}{l}\text { Companion } \\
\text { gender }\end{array}$} & Male & 4 & 1 & \multirow[t]{2}{*}{ n.s ${ }^{V}$} \\
\hline & Female & 3 & 5 & \\
\hline
\end{tabular}

\subsection{Topical features and 'discourse structures' of consultations}

As shown in table 2, there was a significant difference in the ratio of PNES and epilepsy patient consultations undertaken by the two participating doctors. However, no significant differences were found between the discourse spaces of participants in the PNES or epilepsy patient consultations, or between the two participating doctors (see figure 1). 
Figure 1: Discourse spaces: median proportion (\%) of participant contributions ${ }^{*}$

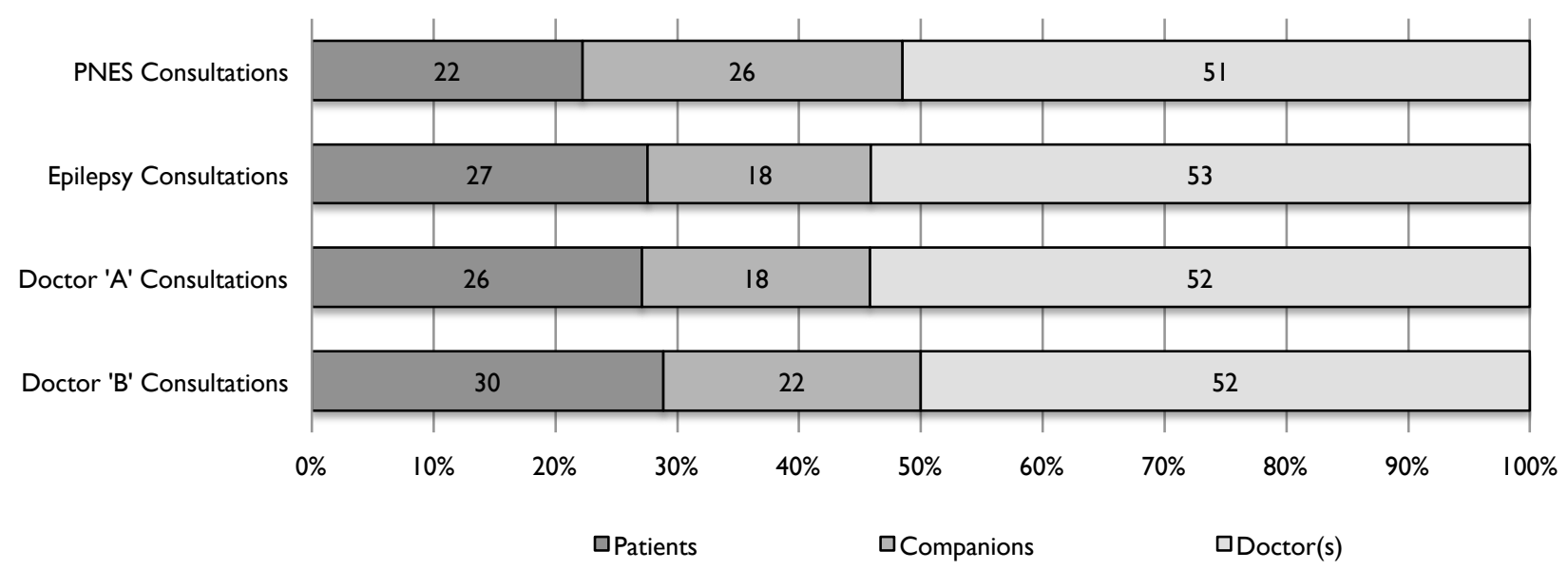

Median calculations mean that figures may not round to 100

Similarly, no differences were identified between the topical content of history-taking phases of consultations undertaken by the two participating doctors, or between the PNES and epilepsy patient consultations. The topical history-taking phases identified in the data reflect those recommended in national epilepsy guidelines (NICE, 2012).

\subsection{Patterns of companion involvement}

The companions of PNES and epilepsy patients tended to become involved in the clinic conversations to describe what they had witnessed based on different 'interactive mechanisms'. Five different patterns of companion involvement were identified.

Companions typically described one to three different seizure events they had witnessed during the course of a single conversation (often describing what they had seen during the patients' first, worst, or most recent seizure episode, or a typical seizure event). The different ways in which companions became involved in interactions to 'gain the floor' and describe what they had witnessed, and how often these mechanisms were observed across all PNES patient consultations and epilepsy patient consultations analysed, are summarised in figure 2, below. 
Figure 2: Patterns of companion involvement in PNES patient and epilepsy patient consultations.

\begin{tabular}{|l|l|l|l|}
\hline Pattern & Companion involvement mechanisms & $\begin{array}{l}\text { Number of times } \\
\text { observed across all } \\
\text { consultations: }\end{array}$ \\
\cline { 3 - 4 } & & $\begin{array}{l}\text { PNES } \\
\text { (total: 7) }\end{array}$ & $\begin{array}{l}\text { Epilepsy } \\
\text { (total: 6) }\end{array}$ \\
\hline A & $\begin{array}{l}\text { After the patient had described at least one seizure event, the } \\
\text { doctor invited the companion to describe what they had } \\
\text { witnessed. }\end{array}$ & 1 & 5 \\
\hline B & $\begin{array}{l}\text { The patient did not volunteer and was not invited by the doctor } \\
\text { to provide a seizure event description. The doctor invited the } \\
\text { companion to describe what they had witnessed, 'bypassing' the } \\
\text { patient. }\end{array}$ & 0 & 2 \\
\hline C & $\begin{array}{l}\text { The patient resisted describing what had happened during } \\
\text { attacks, often despite considerable prompting from the doctor, } \\
\text { and the doctor invited the companion to describe what they had } \\
\text { witnessed. }\end{array}$ & 4 & 0 \\
\hline D & $\begin{array}{l}\text { The patient resisted describing their experiences, often despite } \\
\text { considerable prompting from the doctor, and invited or prompted } \\
\text { their companion to describe what they had seen. }\end{array}$ & 3 & 1 \\
\hline E & $\begin{array}{l}\text { The patient had limited opportunity to describe what they had } \\
\text { experienced because their companion repeatedly intervened } \\
\text { (self-initiated, sometimes taking the patient's turn), and } \\
\text { subsequently described what they had witnessed. }\end{array}$ & 3 & 0 \\
\hline
\end{tabular}

\subsubsection{Typical patterns of companion involvement in epilepsy consultations}

With the exception of one patient, epilepsy patients usually demonstrated little (if any) resistance to doctors' questions about their seizures. In five of six of the epilepsy consultations analysed, the companion waited until they were invited by the doctor to describe what they had witnessed (patterns A and B). Conversely, these patterns were only observed in one consultation of a patient with PNES.

We present verbatim extracts to illustrate our findings; detailed analyses are available as online supplementary material (see table $\mathbf{X X}$ ). In the extracts, $\mathrm{P}$ indicates the patient is speaking, C indicates the companion is speaking, and D indicates the doctor is speaking. 


\section{Pattern A:}

In five epilepsy consultation and only one PNES consultation the companions' described what they have witnessed after the patient had described at least one seizure experience and after the doctor had invited the companion's contribution (as demonstrated in figure 3 , extract 1 ).

\begin{tabular}{|c|c|c|}
\hline \multicolumn{3}{|c|}{ Figure 3, extract 1: Stephen (male), diagnosed with epilepsy. } \\
\hline 41 & P: & It's come up like that, and when I'm getting this \\
\hline 42 & & headache it's all round here, and when it gets really \\
\hline 43 & & bad I'm getting a burning feeling at the back of me eye \\
\hline 44 & & and then if I bend over or owt, I go, I'm out. \\
\hline 45 & D: & ((1 second)) So you pass out when you're bending \\
\hline 46 & & over? \\
\hline 47 & P: & Yeah, well er ((0.5 seconds $))$ the last time I had it \\
\hline 48 & & when l'd just come, er ((0.6 seconds)) \\
\hline 49 & C: & It's not all (the) time is it? \\
\hline 50 & P: & No, no, I, since l've been back out of hospital I've \\
\hline 51 & & had, what, three, three, that's all. \\
\hline 52 & D: & And it's always when you're bending over you get \\
\hline 53 & & this? \\
\hline 54 & P: & Yes, when I've had, l've got that pain and that, \\
\hline 55 & & yeah. \\
\hline 56 & D: & $\begin{array}{l}\text { Um, and you've seen some of the blackouts? } \\
\text { [Doctor turns to face the companion] }\end{array}$ \\
\hline 57 & C: & Normally when \\
\hline 58 & P: & One when, when I got up off of settee after l'd been \\
\hline 59 & & doing that paperwork. \\
\hline 60 & C: & Oh yeah, yeah \\
\hline 61 & & [(remainder of companion's description not shown)] \\
\hline
\end{tabular}

In extract 1 , Stephen completes a description of what he experiences during a typical seizure (to line 55). During the conversation, Stephen finds the design of the doctor's questions (lines 45-46 and 52-53) potentially problematic (the doctor's questions imply that every time Stephen bends over he passes out); and he demonstrates difficulty answering (lines 47-48). In response, Stephen's wife intervenes and "specifies the terms" of the doctor's question (line 49); and Stephen qualifies his ("extended" [21]) responses (lines 50-51 and 54-55). The doctor then invites the companion to contribute to the interaction (in line 56). 


\section{Pattern B:}

In two cases, the doctor 'bypassed' a patient description, and invited the companion to describe what they had seen; however, these patients had stated that they had exclusively experienced epileptic seizures from sleep. This pattern of companion involvement is demonstrated in figure 4 (extract 2).

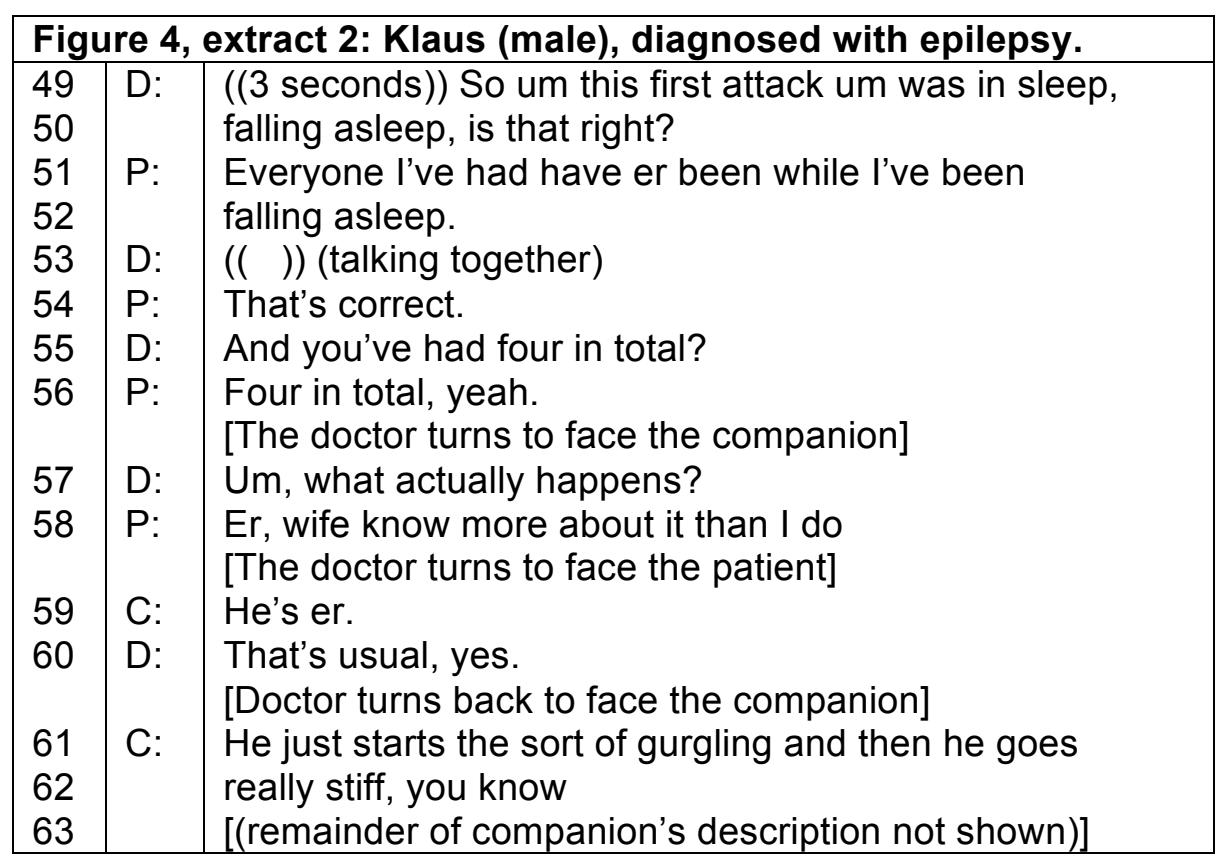

In extract 2, the doctor questions whether a specific seizure ("first attack") occurred whilst Klaus slept (lines 49 to 50 ). Klaus responds by reporting that all his seizures have occurred whilst "falling asleep" (lines 51 to 52). Shortly after learning this, the doctor turns to ask Klaus's companion (wife) what she witnessed (line 57), as opposed to, for example, inviting the patient to describe what he could remember about the experience.

\subsubsection{Typical patterns of companion involvement in PNES consultations}

The companions of PNES patients typically made use of more than one involvement mechanism to secure their contribution to the conversation. The involvement mechanisms most often used by companions in these interactions (patterns $C$ and $D$ ) were usually a consequence of patient 
resistance: in contrast to the majority of epilepsy patients in the sample, most of the PNES patients (five of seven) demonstrated considerable and sustained resistance to doctors' questions about their attacks during the course of their consultations. When doctors in the interactions faced this resistance, often in response to repeatedly prompting the patient to describe an attack, they typically looked to seizure witnesses to describe what they had seen (pattern C). In other cases, patients deferred the doctor's enquiry about their attacks, which had originally been addressed to themselves, to their companion (pattern D). In some cases, the companions of PNES patients persistently intervened in patients accounts without invitation, sometimes to the extent that they eventually took over 'the floor' to describe what they had witnessed (pattern E).

\section{Pattern C:}

In four instances (all in PNES patient consultations), the patient demonstrated considerable resistance to the doctor's enquiries about their seizures (as demonstrated in figures 5 , extract $3 a$ ) and 6 (extract $3 b))$, and their companion was subsequently invited or prompted by the doctor to describe what they had seen (as demonstrated in figure 6, extract $3 b$ ). This pattern of companion involvement was not observed in any of the epilepsy patient consultations.

\begin{tabular}{|l|l|l|}
\hline \multicolumn{3}{|c|}{ Figure 5, extract 3a: Adele (female), diagnosed with PNES } \\
\hline 26 & D: & So these, when, when, when was your last seizure? \\
& & [Patient turns to face the companion] \\
27 & C: & ((1 second $))$ Sunday. \\
28 & P: & Sunday. \\
29 & D: & Mm. ((4 seconds $))$ What can you tell me about that? \\
30 & P: & Um, I don't really remember a lot about them. \\
31 & D: & Mm hmm. \\
32 & P: & Um $((4$ seconds $))$ kind of very, very tired afterwards. \\
33 & & Don't really remember the event before $((1$ second $))$ \\
34 & & leading up to it. \\
35 & D: & Mm. \\
36 & P: & Um $((3$ seconds $))$ obviously while l'm having a seizure, I \\
37 & & never remember what happens during a seizure \\
38 & & $((1$ second $))$ and then normally I need to just sleep. \\
\hline
\end{tabular}

In extract 3a, in response to the doctor's question (line 26), Adele remains silent while turning to face her companion (and prompting him to answer) (line 26 to 27). Adele also "transforms the 
topical agenda" [21] of the doctor's question by generalising from a specific event ("Sunday", lines 27 and 28), to what she could remember about her seizures more generally (“them”, line 30 ).

Adele reports an inability to remember her seizures (line 30), any pre-seizure symptoms (lines 33 and 34), and what happens during a seizure (lines 36 and 37). These types of response have been termed "non-answer" [22] and "strong negative" [23] responses.

Following Adele's sustained resistance to questions about her seizures, the doctor eventually asks her companion what he has witnessed (as demonstrated in figure 6, extract 3b).

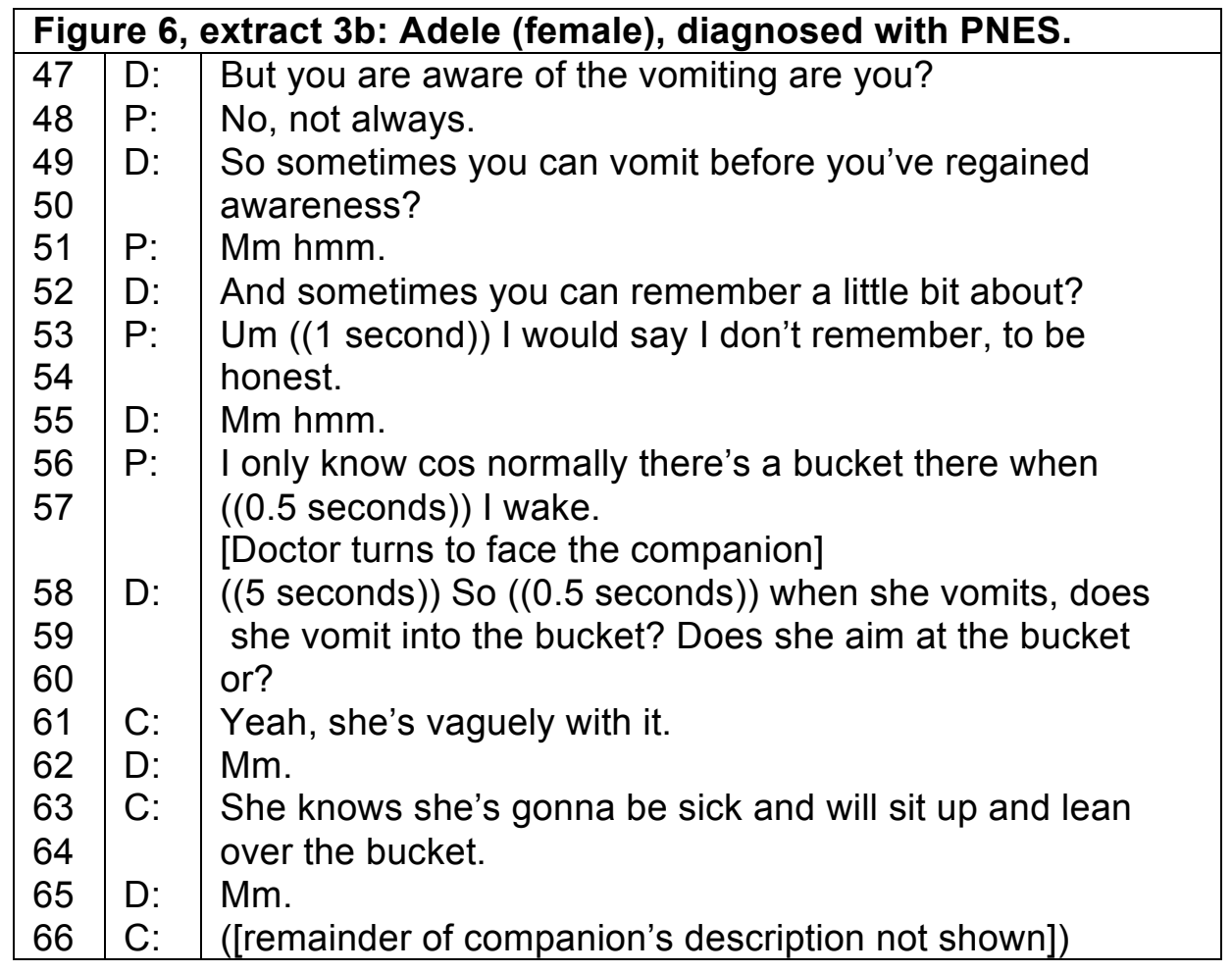

In an attempt to address the ambiguity of Adele's response (at line 48) and her second minimal response (line 51), the doctor asks if Adele, "can remember a little bit about [the vomiting]?" (line 52). Adele responds by reporting an inability to remember (line 53). After facing marked resistance, the doctor eventually turns to face Adele's companion to ask him about Adele's awareness and state (lines 58-60). 


\section{Pattern D:}

In four instances, patients deferred to their companion to answer the doctor's questions, which subsequently led to the companion providing an account of what they had witnessed. This type pattern of companion involvement (as demonstrated in figure 7, extract 4) was observed in three PNES patient consultations and just one of the six epilepsy consultations examined.

\begin{tabular}{|c|c|c|}
\hline \multicolumn{3}{|c|}{ Figure 7, extract 4: Karen (female), diagnosed with PNES. } \\
\hline 184 & D: & $\begin{array}{l}\text { OK. So how often are the blackouts happening now? } \\
\text { [Patient turns to face the companion] }\end{array}$ \\
\hline 185 & P: & ((Laughs)) You'll have to answer that because. \\
\hline 186 & D: & $\begin{array}{l}\text { You know, the collapses where you } \\
\text { [Doctor turns to face the companion] }\end{array}$ \\
\hline 187 & C: & $\begin{array}{l}\text { I reckon er ((sighs)) she, at least once or twice a day. } \\
\text { [Doctor turns to face the patient] }\end{array}$ \\
\hline 188 & D: & So they've increased in frequency? \\
\hline $\begin{array}{l}189 \\
190\end{array}$ & P: & $\begin{array}{l}\text { They are getting worse, yeah, as I told me GP about } \\
\text { that. }\end{array}$ \\
\hline 191 & C: & I, I reckon, I, I, it was twice, one or twice a day. \\
\hline 192 & D: & OK. And then you, you do have these other attacks as \\
\hline 193 & & well, so when did the other attacks start? (( 1 second $))$ \\
\hline 194 & & blackouts started five years ago. \\
\hline 195 & $P:$ & Um ((2 seconds $))$ the, the fit, the actually fitting side of \\
\hline 196 & & it? \\
\hline 197 & D: & Well you've mentioned attacks with seeing stars, you've \\
\hline 198 & & mentioned blank spells, you haven't talked about fitting \\
\hline 199 & & attacks yet. ((1 second)) What happened next, so you \\
\hline 200 & & had the, the blackouts where you collapsed? \\
\hline 201 & P: & $\begin{array}{l}\text { They, then the fitting, then the fits started after that. Um } \\
\text { [Patient turns to face the companion] }\end{array}$ \\
\hline 202 & & ((1 second $))$ and how that come about, um ((3 seconds)) \\
\hline 203 & & I, well (( 3 seconds $))$ it were fitting after weren't it? \\
\hline 204 & C: & Right ((2 seconds)) I've noticed she'll blank out, l'll go \\
\hline 205 & & $(($ patient name $))(($ patient name $))(($ patient name $))$ and \\
\hline 206 & & then I know she's, she, she's going in, into some, some, \\
\hline 207 & & I don't know what you call it, I, I don't know what's wrong \\
\hline 208 & & with her, l'm not a doctor. \\
\hline 209 & D: & Mm. \\
\hline 210 & C: & [(remainder of companion's description not shown)] \\
\hline
\end{tabular}

In response to the doctor asking her about the frequency of her "blackouts" (line 184), Karen turns to look at her companion before beginning to speak. She demonstrates "overt resistance" [23] to the topical agenda of the doctor's question (and provides a "non-answer" and "strong negative" response) by directing her companion to answer on her behalf (line 185). 
At line 202, Karen demonstrates difficulty providing a response to the doctor's question (lines 197200). However, instead of addressing this difficulty (for example, by asking the doctor to clarify what he meant, as she did previously at lines 195-196), Karen (again) defers to her companion to answer (line 203). Responding to Karen's request, the companion begins to offer an account of what he typically witnesses during one of Karen's ("fitting") seizures (lines 204-208), and is subsequently prompted by the doctor to continue with his description (line 209).

\section{Pattern E}

In three exchanges (all in PNES patient consultations), companions self-initiated talk about what they had witnessed and were subsequently prompted by the doctor to continue with, or to elaborate on, their description (pattern E). This pattern of companion involvement, demonstrated in figure 8 (extract 5), was not observed in any of the epilepsy consultations.

\begin{tabular}{|c|c|c|}
\hline \multicolumn{3}{|c|}{ Figure 8, extract 5: Karen (female), diagnosed with PNES. } \\
\hline 17 & D: & So what can you tell me about the first attack? \\
\hline 18 & $P:$ & Er, we got up, the kids were opening their presents \\
\hline 19 & & $((0.5$ seconds $))$ and er we had breakfast, I washed the \\
\hline 20 & & (1) \\
\hline 21 & D: & $\mathrm{Mm} \mathrm{hmm.}$ \\
\hline 22 & $P:$ & And I just went in the room and I felt, just had this \\
\hline 23 & & feeling, and I just dropped on the sofa. \\
\hline 24 & C: & No, you were putting pots in the dishwasher. \\
\hline 25 & P: & Dishwasher, um \\
\hline 26 & C: & And you come in and said "Oh I feel a bit funny." I said \\
\hline 27 & & "Have you been getting up and down, like putting \\
\hline 28 & & things in the dishwasher?" Cos obviously sometimes if \\
\hline 29 & & you stand up too fast it can make you dizzy. \\
\hline 30 & D: & $\mathrm{Mm}$. \\
\hline 31 & C: & Um, he said "not really" and then just dropped and we \\
\hline 32 & & had to, he just laid there, luckily enough he was near \\
\hline 33 & & the pouffe, and he fell onto the pouffe and just laid \\
\hline 34 & & there. Um, we called an ambulance. \\
\hline 35 & D: & Mm. \\
\hline 36 & C & [(remainder of companion's description not shown)] \\
\hline
\end{tabular}

In extract 5, the doctor asks Peter to describe his "first attack" (line 17). Following Peter's response (lines 18 to 23), his wife self-initiates talk that disagrees with his account (from line 24). Peter confirms (at least part of) his companion's description with a partial repetition, "Dishwasher", followed by "um" (line 25); signifying he might have had more to add [24]. However, Peter's wife 
intervenes in his account (only a momentary pause is observed between Peter's use of "um" and his wife resuming her account). The doctor's subsequent use of a continuer (“Mm”, line 30) prompts the companion to continue, who is 'given the floor' to describe what she witnessed (from line 31).

\subsection{Patient resistance}

Patients with epilepsy and PNES were found to respond to doctors' information gathering acts differently, and the ways in which companions became involved in conversations to describe what they had witnessed tended to be associated with the extent to which patients' resisted answering the doctors' questions about their attacks.

Epilepsy patients (including those that experienced seizures whilst they slept) tended to demonstrate low levels of resistance to the doctor's questions about their attacks. In epilepsy patient encounters, resistance to the doctors' questions was usually a consequence of the potentially problematic design, as opposed to the topical agenda, of the question posed. In comparison, PNES patients tended to demonstrate high levels of resistance to the doctors' questions about their attacks; often explicitly stating their inability to answer, deferring to their companion verbally or non-verbally (for instance by using a head-turn; as observed in multi-party conversations with patients with dementia [25-26]) or by transforming the topical agenda of the question posed.

Patients with PNES frequently responded to doctors questions about what had happened during attacks by stating an inability to remember or to know what had happened; for example, "don't really remember”, “I don’t know”, “I really don't know” (as in extracts 3a and 3b).

Patients with PNES have previously been found to use these types of responses in one-to-one doctor-patient interactions. Termed "absolute negations", these include accounts of what seizures are not like, and denials of the ability to remember anything that happened during episodes [1-2, 
27-34] (e.g., as in extract 3a, "I never remember what happens during a seizure", lines 36 to 37). As found in previous research, patients with epilepsy in our data rarely, if ever, responded to a question with an uncontextualised negation.

\subsection{Companion behaviours}

The companions of epilepsy patients were observed to self-initiate talk during patients' accounts of their seizure experiences. However, most of these self-initiations were minimal agreement or acknowledgement tokens that did not interrupt "the flow" [19] of the patient's talk; or which were delivered in response to the patient demonstrating difficulty answering the doctor's questions (as in extract 1).

By comparison, the companions of PNES patients frequently intervened in patients' accounts. Many instances of companion self-initiation appeared to be a consequence of patient resistance to the doctor's questions (as in extracts $3 \mathrm{~b}$ and 4 ), and followed, for example, the patient transforming the topical agenda of the question posed, or claiming an inability to answer. However, in other cases companions' intervened even though patient resistance was not evident (as in extract 5). As well as self-initiating, companions in these exchanges sometimes interrupted the patient's talk, and responded to questions intended for the patient.

When companions intervened, doctors were sometimes observed to try to redirect the conversation back to the patient. However, this technique did not always work, and the companion often continued to intervene and dominate the conversation. These companion behaviours sometimes meant that it was difficult to assess the extent to which patients resisted the doctors' questions.

These behaviours might help to explain why a median of $8 \%$ more of the total discourse space of the PNES consultations was taken up by companion contributions than epilepsy consultations (as detailed in figure 1). 


\section{Discussion and Conclusion}

In this study, patients with PNES but not those with epilepsy tended to exhibit interactional resistance to the doctor's efforts to find out more about their seizure experiences. This observation is very much in keeping with those made in previous studies of dyadic interactions between seizure patients and doctors [1-2, 27-34]. We found that these differences in the interactional behaviour of patients are closely associated with differences in the interactional contributions made by their companions.

\subsection{Practice implications}

In accompanied encounters, doctors might notice that patients with PNES resist answering questions about their seizures, often despite considerable prompting, and have a tendency to respond by stating that they are unable to remember what has happened, or to "transform the topical agenda" [21] of the question posed. They might also invite or prompt their companion to answer questions about their attacks on their behalf. In contrast, doctors might notice that patients with epilepsy are more open to answering questions about their experiences, even if they need to "specify the terms" [21], give "expanded answers" [35] or use "round about trajectories" [23] (typically staying within (or approximate to) "the bounds of the question" [23]) in order to do so. Patients with epilepsy might ask their companion to confirm the accounts they give, but will rarely defer to their companion to answer a question on their behalf.

Doctors may also notice that the companions of patients with PNES may be more inclined to selfinitiate to describe what they have witnessed, to interrupt the patient, or answer questions intended for the patient without being asked to do so. In comparison, the companions of epilepsy patients may be less likely to intervene in patient accounts, and to wait for the doctor to invite them to describe what they have seen. They may, however, offer more minimal agreement or acknowledgement tokens than the companions of PNES patients when patients describe their attacks. 
Our findings make a significant contribution to the literature documenting that linguistic and interactional features can help with the differential diagnostic process: whereas most of the previous findings were based on somewhat "unnatural" research interviews, our findings are based on 'naturally occurring' seizure clinic interactions; more in keeping with a conversation analytic approach [36]. In addition, we have identified new potential diagnostic pointers in consultations involving a patient, a doctor and a companion who had witnessed at least one seizure. In this study, such consultations made up about one third of all new patient presentations in a seizure clinic.

However, despite the diagnostic potential of these conversational pointers, our findings hint at some 'diagnostic losses' in accompanied interactions in this clinical setting. Some of these losses may be attributable to the fact that the doctors in our study were not instructed to maximise patient's opportunity to exhibit the previously described linguistic and interactional diagnostic markers. They were not instructed to follow the unusually open interview procedure used in previous research interviews, but asked to adhere to their usual interview routine [37]. However, as described in a previous quantitative study [15], this qualitative analysis demonstrated how the presence of companions per se limits patients' opportunities to talk about their experiences.

In keeping with the conclusion of a recent review, the doctor may also need explicitly to discuss the desired level of involvement and roles of the companion in the consultation when a seizure witness (or other companion) accompanies the patient [38]. In order to optimise the diagnostic potential of information available from patients, doctors may want to consider initially talking to patients on their own before asking seizure witnesses to join the consultation. As a minimum doctors should make it very clear at the beginning of the interaction, that they are keen to seek a witness account of the seizure eventually, but that it is really important that the patient describes their own seizure experience first (however limited their recall may be). 


\subsection{Limitations}

This pilot study is limited in a number of respects. Despite our substantial initial patient sample, only a modest number of encounters met all inclusion criteria. Participants were aware that the recordings would be used to identify features that might help with the differential diagnosis of attacks. This may have affected how participants behaved in the interactions. Conversations were analysed in depth and in great detail but only a small patient sample was described. Furthermore, the data were analysed by one linguistic rater who was not blinded to diagnosis, and we do not know the inter-rater reliability of the findings at this stage. In addition, two of the patients diagnosed with epilepsy exclusively experienced seizures whilst they slept. For these reasons, the encounters with these patients analysed in this study may not be representative of epilepsy patient encounters in general.

There were no significant differences between the age and gender of participants with epilepsy and PNES in this study. However, data on other (patient and companion) socio-demographic characteristics (for example, level of education, sociocultural and ethnic background) were not collected and these factors may have affected contributions to the interactions.

There was a significant difference in the ratio of PNES and epilepsy patient consultations undertaken by the two doctors participating in this study, and it is possible that some of the interactional differences observed between PNES and epilepsy patients are a consequence of differences in the two doctors' consultation and communication styles. However, there was no significant difference in the median contributions (discourse spaces) of the two doctors to the interactions. In addition, the consultations were topically similar and the topical history-taking phases identified in the data reflected those recommended in national epilepsy guidelines [12]. Both doctors are also experienced seizure experts, male, and in their forties. 


\subsection{Conclusion}

Despite these limitations, this exploratory study extends what is known about interactions between seizure patients, seizure-witness companions and doctors in initial (diagnostic) outpatient seizure clinic encounters. Whilst the presence of companions may limit the doctors' ability to pick up the linguistic and interactional features capable of supporting the differential diagnosis of epilepsy and PNES previously described in one-to-one encounters, the contributions that companions make (in part prompted by patient's interactional behaviour) may provide additional diagnostic pointers. This study has described a number of candidate features, which should be confirmed in larger prospective studies with blinded linguistic raters. 


\section{Regulatory approvals}

South Sheffield NHS Research Ethics Committee gave ethical approval for this study. Sheffield Teaching Hospitals NHS Trust granted research governance approval.

\section{Informed consent and patient details}

All patients and companions gave their written informed consent before participating in the study. All patient/personal identifiers have been removed or disguised so the patient/person(s) described are not identifiable and cannot be identified through the details of the story.

\section{Acknowledgements}

We are very grateful to the patients (and their companions') who agreed to participate in this study, and to the consultant neurologists who agreed to have their practice recorded.

\section{Funding}

This article presents independent research funded by Epilepsy Action. 


\section{References}

[1] M. Schwabe, M. Reuber, M. Schoendienst, E. Guelich, Listening to people with seizures: how can linguistic analysis help in the differential diagnosis of seizure disorders?, Comm Med. 5, 2008, 59-72.

[2] M, Reuber, C. Monzoni, B. Sharrack, L. Plug, Using interactional and linguistic analysis to distinguish between epileptic and psychogenic nonepileptic seizures: A prospective, blinded multirater study, Epilepsy \& Behav. 16, 2009, 139-144.

[3] C. Robson, P. Drew, T. Walker, M. Reuber, Catastrophising and normalising in patient's accounts of their seizure experiences, Seizure. 21, 2012, 795-801.

[4] D. Jones, P. Drew, C. Elsey, D. Blackburn, S. Wakefield, K. Harkness, M. Reuber, Conversational assessment in memory clinic encounters: interactional profiling for differentiating dementia from functional memory disorders. Aging Ment Health, 2010, 1-10. Available online ahead of print at: http://www.ncbi.nlm.nih.gov/pubmed/25803169

[5] C,M. Cornaggia, S.C. Gugliotta, A. Magaudda, R. Alfa, M. Beghi, M. Polita, Conversation analysis in the differential diagnosis of Italian patients with epileptic or psychogenic non-epileptic seizures: A blind prospective study, Epilepsy \& Behav. 25 (2012) 598-604.

[6] M. Reuber, Psychogenic nonepileptic seizures: answers and questions, Epilepsy \& Behav. 12, 2008, 622-635.

[7] R.P. Lesser, Treatment and Outcome of Psychogenic Nonepileptic Seizures, Epilepsy Curr. 3, 2003, 198-200.

[8] H. Angus-Leppan, Diagnosing epilepsy in neurology clinics: a prospective study, Seizure. 17 (2008) 431-436.

[9] I.A. Kotsopoulos, M.C. de Krom, F.G. Kessels, J. Lodder, J. Troost, M. Twellaar, T. van Merode, A.J. Knottnerus, The diagnosis of epileptic and non-epileptic seizures, Epilepsy Res. 57, 2003, 59-67.

[10] K. Malmgren, M. Reuber, R. Appleton, Differential diagnosis of epilepsy, in: S. Shorvon, M. Cook, R. Guerrini, S. Lhatoo (Eds.), Epilepsy: Oxford Textbook of Clinical Neurology Series, Oxford, 2012, pp. 81-94.

[11] D. Smith, B.A. Defalla, D.W. Chadwick, The misdiagnosis of epilepsy and the management of refractory epilepsy in a specialist clinic, QJM-INT J MED. 92, 1999, 15-23.

[12] National Institute for Clinical Excellence, The epilepsies: the diagnosis and management of the epilepsies in adults and children in primary and secondary care, Clinical Guideline 137, 2012.

[13] J.P. Leach, R. Lauder, A. Nicolson, D.F. Smith, Epilepsy in the UK: misdiagnosis, mistreatment, and undertreatment? The Wrexham area epilepsy project, Seizure. 14, 2005, 514520.

[14] F.A. Chowdhury, L. Nashef, R.D.C. Elwes, R.D.C, Misdiagnosis in epilepsy: a review and recognition of diagnostic uncertainty, Eur J Neurol. 15 (2008) 1034-1042.

[15] C. Robson, P. Drew, M. Reuber, Duration and structure of unaccompanied (dyadic) and accompanied (triadic) initial outpatient consultations in a specialist seizure clinic. Epilepsy Behav. 27, 2013, 449-454.

[16] C, Roberts, S, Sarangi, Theme-oriented discourse analysis of medical encounters, Med Educ. 39, 2005, 632-640.

[17] P. Drew, J. Heritage, J. Conversation Analysis, Volumes 1-4, Sage benchmarks in social research methods. SAGE Publications Ltd, 2006.

[18] J. Heritage, D.W. Maynard (Eds.), Communication in Medical Care: Interaction Between Primary Care Physicians and Patients. Cambridge University Press, Cambridge, 2006.

[19] E, Goffman, Forms of Talk, University of Pennsylvania Press, Philadelphia. 1981.

[20] C. Edelsky, "Who's got the floor?", Lang in Soc. 10 (1981) 383-421.

[21] T. Stivers, M. Hayashi, Transformative answers: One way to resist a question's constraints, Lang Soc. 39, 2010, 1-25.

[22] T. Stivers, J. Robinson, A preference for progressivity in interaction. Lang Soc. 35. 2006, 367392.

[23] S, Clayman. Answers and evasions, Lang Soc. 30 (2001) 403-442.

[24] H.H. Clark, J.E. Fox Tree, Using uh and um in spontaneous speaking, Cognition. (2002) 84 73-111. 
[25] T. Fukui, T. Yamazaki, R. Kinno, Can the 'Head-Turning Sign' Be a Clinical Marker of Alzheimer's Disease. Dement Geriatr Cogn Disord Extra. 1 (2011) 310-317.

[26] A.J. Larner, Head turning sign: pragmatic utility in clinical diagnosis of cognitive impairment, J Neurol Neurosurg Psychiatry. 83, 2012, 852-853.

[27] E. Guelich, M, Schoendienst, "Das ist unheimlich schwer zu beschreiben".

Formulierungsmuster in Krankheitsbeschreibungen anfallskranker Patienten:

differentialdiagnostische und therapeutische Aspekte, Psychother Sozialwissensch Zeitschr qualitat. 1 (1999) 199-227.

[28] M. Schoendienst, Zur Differentialdiagnose nächtlicher anfallsartiger Störungen, Akt Neurol. 28, 2001, 33-36.

[29] I. Furchner, Keine Absence gleicht der anderen, in: G. Bruenner, E. Guelich (Eds.), Die

Darstellung von Bewusstseinslu ecken in Anfallsbeschreibungen. Krankheit verstehen.

Interdisziplinaere Beitraege zur Sprache in Krankheitsdarstellungen. Bielefeld: Aisthesis, 2002.

[30] V. Surmann, Anfallsbilder. Metaphorische Konzepte im Sprechen anfallskranker Menschen.

Koenigshausen \& Neumann, Wuerzburg, 2005.

[31] M. Schwabe, S.J. Howell, M. Reuber, Differential diagnosis of seizure disorders: A

conversation analytic approach, Soc Sci Med. 65, 2007, 712-724.

[32] L. Plug, B. Sharrack, M. Reuber, Seizure, fit or attack? The use of diagnostic labels by patients with epileptic and non-epileptic seizures, Appl Linguist. 31, 2009, 94-114.

[33] L. Plug, B. Sharrack, M. Reuber, Seizure metaphors differ in patients' accounts of epileptic

and psychogenic non-epileptic seizures, Epilepsia. 50, 2009, 994-1000.

[34] L. Plug, B. Sharrack, M. Reuber, Metaphors in the description of seizure experiences:

Common expressions and differential diagnosis', Lang Cogn. 3, 2011, 209-234.

[35] T. Stivers, J. Heritage, Breaking the sequential mould: Answering 'more than the question'

during comprehensive history taking, Text. 21, 2001, 151-185.

[36] R. Wooffitt, Conversation analysis and discourse analysis: A comparative and critical introduction. Routledge, London, 2005.

[37] M, Reuber and K. Ekberg, Das Potential soziolinguistischer interaktionaler Beiträge zur

Differentialdiagnose epileptischer und nicht-epileptischer Anfälle in der Neurologieambulanz, in: T.

Spranz-Fonagy, A. Busch (Eds.), Handbuch Sprache und Medizin, De Gruyter: Berlin, (in press).

[38] R.C. Laidsaar-Powell, P.N. Butow, S. Bu, C. Charles, A. Gafni, W.W.T. Lam, J. Jansen, K.J.

McCaffery, H.L. Shepherd, M.H. Tattersall, I, Juraskova, Physician-patient-companion

communication and decision-making: A systematic review of triadic medical consultations, PEC. 91, 2013, 3-13.

[39] D. Edwards, A, Fasulo, "To be honest": Sequential uses of honesty phrases in talk-ininteraction. Res Lang Soc Interac. 39, 2006, 343-376.

[40] M. Haakana, Laughter in medical interaction: From quantification to analysis, and back, J Socioling. 6, 2002, 207-235.

[41] G, Jefferson, Caveat speaker: A preliminary exploration of shift implicative recipiency in the articulation of topic (Final Report). Social Science Research Council, The Netherlands, 1981. 